\title{
Apokaliptično dojemanje stvarnosti v drami Mihaila Bulgakova Beg
}

\author{
Natalia Kaloh Vid \\ Univerza v Mariboru, Filozofska fakulteta, Koroška cesta 160, \\ SI-Maribor,natalia.vid@siol.net
}

\begin{abstract}
Članek obravnava zgodovinsko-filozofsko videnje Mihaila Bulgakova v drami $B e g$, posvečeni državljanski vojni. Avtorica ugotavlja, da pisateljevo ustvarjalno misel opredeljuje apokaliptično dojemanje stvarnosti. Siže drame Bulgakov vzpostavi kot projekcijo Janezovega razodetja in se $\mathrm{v}$ tekstu večkrat sklicuje na apokaliptično prerokbo. Zgodovinska apokalipsa v drami predpostavlja razpad starega sveta, ki ga zaznamujejo izguba domovine, izguba lastne identitete, oskrunitev vseh starih idealov in izmaličenje človeške podobe.
\end{abstract}

The article analyzes the historical and philosophical position of Mikhail Bulgakov as reflected in the drama Beg, which depicts the last days of the civil war in Russia. The author states that Bulgakov's creative vision is influenced by apocalyptic thinking. The drama is based on Revelation and includes numerous allusions to the apocalyptic prophecy. As a result of the historical apocalypse, the norms of the previous life are destructed. The destruction of the old world is signified by loss of homeland and identity as well as by the destruction of the human soul.

Ključne besede: Bulgakov, drama Beg, apokalipsa, aluzija

Key words: Bulgakov, drama Beg, revelation, allusion

\section{Uvod}

Začetek dvajsetega stoletja se je v rusko zgodovino zapisal kot eshatološko obdobje viharnih socialnih, političnih in verskih sprememb, kaotičnih in okrutnih. Oktobrski revoluciji leta 1917 je sledila skoraj petletna državljanska vojna, ${ }^{1}$ nato obdobje NEP-a (nove gospodarske politike) in Stalinove oblasti.

\footnotetext{
${ }^{1}$ Državljanski vojni sta posvečena Bulgakovov roman Bela Garda in drama Beg.
} 
Družbene in politične spremembe so v omenjenem obdobju odločilno vplivale na rusko kulturo, saj je tok zgodovinskih dogodkov do določene mere sovpadal $\mathrm{z}$ apokaliptično prerokbo konca sveta, zapisano v Janezovem razodetju, ki je v ustvarjalnosti ruskih pisateljev in filozofov z začetka dvajsetega stoletja, t. i. srebrnega obdobja ruske kulture, dobilo osrednji pomen. Članek se osredotoča na analizo apokaliptičnega konteksta v drami velikega ruskega umetnika Mihaila Bulgakova Beg, posvečeni državljanski vojni. Ob tem je potrebno poudariti, da se je poetika »apokaliptičnega« v Bulgakovovi ustvarjalnosti pojavila kot izraz pisateljevega eshatološkega nazora. Sodil je med prvo generacijo sovjetskih umetnikov, ki so po revoluciji in državljanski vojni živeli in ustvarjali v nepredušnem sovjetskem prostranstvu »za železno zaveso«, kjer ni obstajala svoboda misli in duha. V svojih literarnih delih Bulgakov namensko vzpostavi povezave $z$ apokaliptično prerokbo, saj vidi številne podobnosti med zgodovinsko situacijo v tedanji Sovjetski zvezi in apokaliptičnimi dogodki, opisanimi $\mathrm{v}$ Janezovem razodetju. Zavedal se je duhovne in moralne razkrojenosti, ki je prizadela sovjetsko ljudstvo, in čutil katastrofalne posledice revolucije in državljanske vojne za prihodnje generacije. Zaradi svoje nepristranske želje po upodobitvi resnice pa je veljal za »problematičnega« in »ideološko sumljivega«. Prizadeval si je namreč, da bi sovjetske bralke in bralce otresel ideološkega vpliva in jim sovjetsko stvarnost prikazal takšno, kot je bila v resnici. Modificirana, dekanonizirana projekcija apokaliptične prerokbe, ki se pojavlja od prvih povesti do zadnjega romana, poroča o pisateljevem poskusu razumeti in ovrednotiti obdobje moralne in duhovne razkrojenosti, v katerem je bil prisiljen živeti. ${ }^{2}$ Ustvaril je svojo verzijo zgodovine - zgodovine, zaznamovane $\mathrm{z}$ apokalipso, obenem pa se je $\mathrm{v}$ iskanju odgovorov na vprašanja o resnici, o smislu človeškega življenja in o koncu sveta osredotočil na lajtmotivne teme in podobe, med katerimi prevladujejo apokaliptične.

\section{Mihail Bulgakov in njegova dela}

Prozni opus Mihaila Afanasijeviča Bulgakova obsega tri romane, več povesti (med njimi dve znanstvenofantastični), feljtonov in dram. ${ }^{3} \mathrm{~V}$ avtobiografski del Bulgakovove ustvarjalnosti se uvrščajo Zapiski mladega zdravnika ${ }^{4}$ ter štiri delno avtobiografske kratke povesti: Morfij, Nenavadne dogodivščine doktorja, Rdeča krona in Ubil sem. Že v tej zgodnji fazi se izoblikujejo motivi, ki kasneje postanejo stalnica Bulgakovove ustvarjalnosti. Med njimi dobi osrednjo vlogo motiv krivde in odgovornosti posameznika za svoja dejanja, ki največjo

\footnotetext{
${ }^{2}$ Bulgakovova mitologizacija v romanih Bela Garda ter Mojster in Margareta je podrobno analizirana v monografiji Mihe Javornika Evangelij Bulgakova (1994).

${ }^{3}$ Eno najbolj znanih Bulgakovovih biografij Žizneopisaniye Mikhaila Bulgakova (1988) je napisala Marietta Čudakova.

${ }^{4}$ Veliki ruski umetnik je svojo poklicno pot začel kot zdravnik, ko je na začetku prve svetovne vojne delal na podeželju, v času državljanske vojne pa je bil vpoklican v vojsko.
} 
razsežnost doseže v drami Beg. Prav v zgodnji prozi Bulgakov vzpostavi najpomembnejši temelj svoje poetike - pomen etične in moralne komponente, ki jo mora človek ohraniti tudi v času svetopisemske katastrofe, ki docela uničuje osnove prejšnjega življenja.

Napisal je tri romane. Bela garda pripoveduje o človeški usodi v času državljanske vojne med boljševiki in belogardisti v Ukrajini; nedokončani Gledališki roman je zasnovan na avtorjevih lastnih izkušnjah s cenzuro v sovjetskem gledališkem prostoru; zadnji roman Mojster in Margareta, večplastna naracija z elementi menipejske satire, pa se osredotoči na usodo umetnika v Sovjetski zvezi.

Večina Bulgakovovih dramskih del (Aleksander Puškin, Zarota svetohlincev, Adam in Eva Blaženstvo, Ivan Vasiljevič spremeni poklic, Batum, Beg itd.) zaradi konflikta $\mathrm{z}$ uradno cenzuro v času pisateljevega življenja ni bila uprizorjena ali natisnjena. Edina Bulgakovova drama, ki je po več cenzurnih posegih doživela večji uspeh na gledaliških odrih še v času pisateljevega življenja, je drama Dnevi Turbinovih, napisana po literarni predlogi Bele garde.

Bulgakovov spor s sovjetsko cenzuro mu je sčasoma skoraj popolnoma onemogočil objavljanje. Pisal je Iosifu Stalinu in zaprosil za emigracijo, ki mu je niso odobrili. Preživljal se je s pisanjem za različne časopise in revije. Po dolgi bolezni je umrl leta 1940 v Moskvi, do zadnjega dneva pa je vnašal popravke v svojo zadnjo veliko mojstrovino Mojster in Margareta, katere naslovni junak se ne želi imenovati pisatelj, saj je ta beseda postala sinonim za nekoga, ki je podlegel sovjetskemu cenzurnemu stroju. Ob Bulgakovovi smrti ga širše občinstvo skoraj ni poznalo.

\section{Drama Beg: usoda človeka v apokaliptičnem svetu}

V Bulgakovovih delih, ki tematizirajo državljansko vojno, je tema konca sveta tesno povezana $\mathrm{z}$ avtorjevim odnosom do zgodovine in usode človeka, ki se je znašel v središču zgodovinskih procesov. Ta odnos opredeljuje dialog med mitološko-večnim in zgodovinsko-konkretnim kontekstom, ki omogoča dvojno perspektivo umetniške realnosti (Jablokov 1992: 98). S pomočjo arhetipskih situacij, biblijskih simbolov, lajtmotivnih podob in metatekstualnih elementov Bulgakov objektivne, realne, konkretno-zgodovinske situacije zmeraj uvršča v skupni mitološki kontekst, ki njegovo vizijo približa drugim velikim pisateljem dvajsetega stoletja (Kafki, Mannu, Joyceu). Obenem umetniški svet Bulgakova opredeljuje unikatna združitev kozmičnega in zemeljskega, zgodovinskega in človeškega, mita in določene človeške usode, arhetipa in neponovljive človeške osebnosti.

Eno pomembnejših vprašanj v zgodovinskofilozofski koncepciji Bulgakova, še posebej jasno zarisano $\mathrm{v}$ delih o državljanski vojni, se vzpostavi v navezavi na usodo človeka, ki je prisiljen živeti v kaotični, apokaliptični stvarnosti. V Bulgakovovi ustvarjalnosti se zmeraj prelamlja spoznanje o vrednosti posameznega človeškega življenja, saj se v središču dogajanja vedno znajde posa- 
meznik, ki pogosto podleže nekontrolirani zgodovinski stihiji. Spopad človeka $\mathrm{z}$ uničujočo silo revolucije in vojne je ena osrednjih tem v drami $B e g$, ki se tematsko navezuje na pisateljev prvi roman Bela gardo.

$\mathrm{V}$ obeh delih izstopa vrsta skupnih vsebin, zajetih iz iste/skupne zgodovinske snovi, ki jo avtor tudi oblikuje $\mathrm{v}$ istih apokaliptičnih motivih (zver, tema, apokaliptični jezdec, božje kazni, čaša gneva itd.) ter v idejno podobnih interpretacijah tem. Podoba zgodovinske apokalipse, ki se razgrne že v Beli gardi, v Begu doseže vrhunec. Dokončni razpad starega sveta zaznamujejo izguba domovine, izmaličenje človeške podobe ter oskrunitev vseh starih idealov. Zavest o naraščanju stihijskosti in kaotičnosti, o izgubljanju upanja in vere pogojuje Bulgakovovo prepričanje $\mathrm{v}$ katastrofalne posledice revolucije in državljanske vojne.

Če se v Beli gardi na tematsko-idejni ravni uresničuje napoved, ki jo nosi apokalipsa, je v Begu poudarjena ponovljivost razmerij in posledično tipskost vlog, dodeljenih posameznikom v zgodovini in kulturi. V drami, ki jo odlikuje čustvena in moralna razdvojenost $\mathrm{v}$ doživljanju glavnih likov, se Bulgakov osredotoči na problematiko osebne odgovornosti vsakega posameznika za svoja dejanja. Ob tem še posebej izpostavi etična načela, ki bi jim človek moral zmeraj slediti.

Drama Beg, ki v času Bulgakovovega življenja nikoli ni bila uprizorjena na gledaliških odrih, se odvija na realnem zgodovinskem ozadju državljanske vojne in opisuje njeno zadnjo etapo, ko so ostanki belogardistične vojske bežali iz Ukrajine v Konstantinopel. Osrednjo vlogo dodeli okrutnemu generalu Hludovu, »zveri«, ki v zadnjih dnevih pred umikom bele garde pobija nedolžne ljudi in $v$ tem vidi služenje svoji domovini. Med drugim ukaže kazen poslanika Krapilina, ki se kasneje prične pojavljati v njegovih sanjah in »kot senca bega njegovo prebujeno vest « (Skaza 1979/80: 156). Na koncu drame se Hludov odloči vnovič povezati svoj razklani jaz na edini način, ki mu preostane, in stori samomor.

Bulgakovova drama ruši ideološko usmerjeno tabuizirano vprašanje o vlogi in poslanstvu belogardistov, ki so jih sovjetski pisatelji in zgodovinarji predstavljali kot izdajalske pošasti, ki so zatirale pot novi svobodni sovjetski državi. Dejstvo, da so se belogardisti borili za svojo domovino in, če ne drugo, da so si zaslužili pravico vsaj do objektivne ocene njihovega poslanstva, je bilo $\mathrm{v}$ uradnem sovjetskem diskurzu popolnoma prezrto. V nasprotju z uradno začrtanimi smernicami si Bulgakov ne prizadeva za to, da bi z argumentacijo obranil eno ali drugo ideološko in politično pozicijo, ki jo je v resnici zelo težko zgodovinsko celovito osvetliti in utemeljiti. Idejne, ideološke in politične delitve znotraj naroda ga ne zanimajo in drama $B e g$ tematizira predvsem usodo posameznika, ujetega $\mathrm{v}$ vihar zgodovine, ob tem pa $\mathrm{v}$ ospredje postavlja $\gg$ absolutno etično kvaliteto« (Skaza 1979/80: 157). Drama skozi usode junakov v svoji zgodovinsko-spoznavni razsežnosti pripelje bralca do sklepa, da vprašanje o tem, kdo je zmagal v državljanski vojni, ni bistveno. 


\section{Funkcije epigrafa}

Vsako dejanje drame ima svoj epigraf, toda najpomembnejši je zagotovo skupni, ki nakazuje Bulgakovovo težnjo slediti literarni tradiciji svojih predhodnikov in aktualizirati njihove zamisli v sodobnem kontekstu. ${ }^{5}$ Vrstice iz pesmi Vasilia Žukovskega Певеи во Стане Русских Войнов (Pevec v stanu ruskih vojščakov), »Бессмертье - тихий, светлый брег, / Наш путь - к нему стремленье, / Покойся, кто свой кончил бег!«, imajo poseben pomen v Bulgakovovi ustvarjalnosti, saj so večkrat omenjene v njegovih dnevniških zapiskih. ${ }^{7}$

Veliko znanstvenikov (med drugimi tudi Javornik in Himič) opozarja na namensko orientacijo Bulgakova na mite, sižeje in podobe predhodnih kultur pri ustvarjanju lastnega zgodovinskega prostranstva (Himič 2003: 259-260; Javornik 1994: 190-193). Potemtakem se Bulgakov ne omejuje na presojanje določene zgodovinske situacije zgolj s svojega subjektivnega stališča, temveč vidi in ocenjuje svoj zgodovinski čas v kontekstu neomejenega kozmičnega prostranstva, v katerega je umeščeno posamezno zgodovinsko dogajanje. Težnja Bulgakova, da bi upodobil večne teme in podobe, neomadeževane etične kategorije in univerzalne kozmične modele, obenem pa vzpostavil pretrgane kulturne vezi, je razumljiva. Svet, v katerem je živel in ustvarjal, je postajal vedno bolj neurejen in kaotičen. Katastrofalnost realnih zgodovinskih dogodkov je omajala človeško vero v razsodnost zgodovine, nesmiselne, pretrgane, kaotične in apokaliptične v svoji razsežnosti in posledicah. Da bi na novo vzpostavil razblinjeno celostnost dojemanja in bralce vrnil k tradiciji, Bulgakov namensko umešča svoja dela $\mathrm{v}$ svetovni kulturni kontekst in se zgleduje po svojih predhodnikih.

$\mathrm{V}$ pesmi Pevec v stanu ruskih vojščakov nastopi prerok, ki nagovori rusko vojsko in jo spomni na številne krvave upore in bitke na ruskem ozemlju, obenem pa občuduje močni in nepremagljivi ruski duh. Vrstice iz pesmi Žukovskega se pri Bulgakovu pojavijo v kontekstu refleksij o zadnji etapi državljanske vojne in kažejo na pisateljev namen povezati zgodovinsko preteklost in sedanjost Rusije v edino, apokaliptično vizijo. Podobno kot v Beli gardi epigraf opredeljuje Bulgakovovo videnje zgodovine svoje države, ujete v neprestane bitke, neskončno rušenje in smrt. Zgodovinska usoda Rusije se v navezavi na epigraf zariše kot neskončni ciklus svetopisemskih katastrof, ki prinašajo smrt, razklanost in propad.

Osrednji pomen v pesmi ima motiv pokoja za tiste, ki so končali služenje svoji domovini. V filozofskem polju Bulgakovove drame pojem beg potemtakem

\footnotetext{
${ }^{5}$ V epigrafu k romanu Bela Garda se Bulgakov sklicuje na Puškinovo povest Stotnikova hči.

${ }^{6}$ Nesmrtnost je tihi, svetli breg, / naša pot je hrepenenje po njem, / počivaj tisti, ki je končal svoj beg. V ruščini ima glagol покойся dva pomena, 'počivaj' ali 'najdi svoj mir po smrti'.

${ }^{7}$ Marietta Čudakova podrobno analizira vpliv te pesmi na Bulgakova (Čudakova 1988: $362-363)$.
} 
ne pomeni le emigracije in umika poražene bele garde, temveč se navezuje na usodo slehernega posameznika, zaznamovano s trpljenjem, preizkušnjami in neskončnim begom k večnemu pokoju. Motiv utrujenosti kasneje dobi osrednjo vlogo v Bulgakovovem zadnjem romanu Mojster in Margareta. Epigraf prav tako uvede zapleteno in večplastno temo nesmiselnosti bega človeka pred zgodovino in usodo.

Pesem Žukovskega, ki je v originalu stilizirana kot starinska ruska zahvalna pesnitev, razkriva še eno pomembno intertekstualno vzporednico. Epigraf ohrani žanrski spomin ode, ki opisuje neskončne slavnostne bitke in zmage na ruski zemlji. S svojo vzvišeno intonacijo in slavnostno leksiko vzbudi določena pričakovanja $\mathrm{v}$ bralcu, ki je seznanjen $\mathrm{z}$ osnovnimi zakonitostmi ode, ki tematizira plemenita dejanja glavnega junaka, njegovo žrtvovanje in neizmerno ljubezen do domovine. V nasprotju s tradicionalno podobo osrednji lik drame $B e g$, vojščak novega časa, belogardistični general Hludov, še zdaleč ni požrtvovalen in plemenit človek. Bulgakov ga imenuje »šakal« in »zver«, med dramo pa se razkrije, da je odgovoren za smrt številnih nedolžnih ljudi. S pomočjo epigrafa jasno zarisana distinkcija med plemenitim junakom ode in zgodovinskim likom generala Hludova uvede zanimiv, lahko bi rekli ironični kontrast. Junak starih ruskih od, pozvan k varovanju svoje domovine in ljudstva, se po volji nenasitne zgodovinske usode spremeni v rablja Hludova, v resnici bolnega in nesrečnega človeka, ki se oklepa svoje vloge »šakala« in »zveri«, saj vidi prav v obešanju nedolžnih služenje svoji domovini.

$\mathrm{V}$ navezavi na zgodovinsko vlogo generala Hludova se v dramskem tekstu pojavi še ena ambivalentna aluzija. Drugo dejanje se odvija v belogardističnem štabu, na steni katerega je slika Georgija Zmagovalca - zaščitnika Rusije, ki bi moral simbolično predstavljati samega generala. Toda v resnici je Hludov neusmiljeni morilec, ki potepta še zadnje ostanke človeškosti v sebi, da bi do konca odigral svojo zgodovinsko vlogo. Njegova dejanja usmerja temačen občutek zavedanja svoje zmote, ki ob koncu povzroči izgubo razuma in ga pripelje k samomoru. Bulgakov s podobo generala Hludova izpostavi problematiko nravstvenega izbora človeka, ki bi moral kljub zgodovinskim grozotam ostati v prvi vrsti človek. Alexander Skaza ugotavlja, da drama Beg, »/.../ obnavlja pisateljev ideal čiste človečnosti« (1979/80: 157), eno najbolj izstopajočih motivacij Bulgakovove proze in dramaturgije.

\section{Apokaliptične aluzije $v$ drami}

Drama je napisana v obliki osmih sanj, ${ }^{8} \mathrm{ki}$ imajo posebno funkcijo in se odvijajo kot analogija na znane biblijske zgodbe: svetovni požar (1. sen), sodni dan (2.-3. sen), izhod (4. sen), iskanje obljubljene dežele (5.-7. sen), načrtovanje vrnitve v Novi Jeruzalem (8. sen). Takšnega biblijsko zasnovanega odnosa do pojmovanja in uprizarjanja zgodovinske stvarnosti v tedanji sovjetski dramaturgiji ni bilo. S

\footnotetext{
${ }^{8}$ Drama ima podnaslov: Osem sanj. Drama v petih dejanjih.
} 
svojim razumevanje zgodovine skozi prizmo univerzalnih biblijskih sižejev se Bulgakov razlikuje od večine ateističnih sovjetskih umetnikov, ki so se karseda dosledno izogibali sklicevanjem na svetopisemska besedila. ${ }^{9}$

Poleg citata - epigrafa predstavljajo glavni intertekstualni postopek aluzije na Razodetje, ki so prisotne na vseh tekstovnih ravneh in so večinoma ambivalentne narave. Pojavijo se že v prvem dejanju, ki se odvija v podzemeljskem samostanu, kjer se pred boljševiki skrijejo ubežniki. Uvodni del - dogajanje v samostanu - je svojevrstna ekspozicija, ki vpeljuje ključne apokaliptične aluzije. Irealno začrtano klavstrofobično prostranstvo samostana pokriva apokaliptična tema: »Peti je izlil svojo čašo na prestol zveri in njeno kraljestvo je pokrila tema« (Razodetje: 16: 10). Slišati je zvoke molitev, menihi se pojavijo in izginejo kot prikazni v soju sveč, v oknu so vidni bliski požara, slišni so gromi in glasovi: »Nato je angel vzel kadilnico, jo napolnil z oltarja ter jo vrgel na zemljo. In nastali so gromi in glasovi, bliski in potres« (Razodetje: 8:5). Vse je zalito z rdečkasto svetlobo, zunaj pada dež in sneg. Junaki, ki že več dni bežijo pred grozotami državljanske vojne, se poskušajo skriti v tej nezanesljivi barki, ki predstavlja zadnje zavetišče pred koncem sveta. Že v začetku drame se pojavi aluzija na križev pot, namenjen tistim, ki so se slučajno znašli v zgodovinskem viharju. Vsesplošni občutek nočne more poudari dejstvo, da postajajo priče grozovitih zgodovinskih dogodkov vedno bolj izgubljene v času in prostranstvu in se vedno bolj odmikajo v svet blodenj in sanj. Eden osrednjih dramskih likov, Sergey Golubkov, že v prvih vrsticah pove: »Skoraj mesec že beživa /.../ in vse okoli nas postaja vedno bolj nejasno « (218). Slutnja neizogibne katastrofe postane realnost na koncu prvega dejanja, ko prispe novica o bližajočem se napadu boljševikov. Pripuščeni na milost Rdeče armade menihi pričnejo moliti za odrešitev.

Eden priljubljenih motivov v Bulgakovovi ustvarjalnosti je motiv sovražne stihije, preko katerega se drama intertekstualno navezuje na Puškinovo povest Stotnikova hči, ki tematizira veliki punt ruskih kmetov v osemnajstem stoletju, ki ga je organiziral Jemeljan Ivanovič Pugačov. Puškinova povest se prav tako odvija pozimi in tematizira krvavi in neusmiljeni ruski punt, ki se kot državljanska vojna vnovič ponavlja v začetku dvajsetega stoletja. Pri Bulgakovu nenavadni vremenski pojavi in nekontrolirana stihija skozi čas spremljajo obdobja zgodovinskega zloma in izgube prave poti. Pojavijo se tudi na začetku drugega dejanja v podobah zverinskega mraza, ki je okoval železniško postajo, kjer se nahaja belogardistični štab.

Glavno prizorišče drugega dejanja - štab poražene bele garde - vnovič odlikujejo apokaliptične aluzije: električna svetloba je podobna apokaliptičnemu plamenu, dve zeleni luči spominjata na oči zveri, pojavijo se ognjena svetlikanja, podobna zmajem..$^{10}$ General Hludov, »bolni človek, bolni od nog

\footnotetext{
${ }^{9}$ Eno redkih izjem predstavlja Vladimir Majakovsky in njegova drama Misterija-Buff.

${ }^{10}$ Podoba železniške postaje pri Bulgakovu vedno predstavlja aluzijo na satansko orožje, okovano v železniški oklep in pripravljeno na boj: »Imele so nekakšne železne oklepe, zvok njihovih perutnic pa je bil kakor ropot bojnih vozov z mnogimi konji, ki drvijo v boj« (Razodetje: 9: 9).
} 
do glave« (227), opravlja sodišče, ki predstavlja ambivalentno aluzijo na sodni dan iz Razodetja. V drugem dejanju je namreč opisan zadnji dan generala Hludova in ostankov bele garde pred dokončnim porazom in umikom $\mathrm{v}$ tujino. Razočaran in obupan zaradi lastne nemoči poskuša Hludov do konca odigrati svojo zgodovinsko vlogo, ob tem pa se razglasi za božje orožje in si prilasti pravico soditi nedolžnim ljudem. Sledi srečanje s poslanikom Krapilinom, ki Hludova označi kot zver (aluzija na Razodetje) in mu napove bližajoči se konec: ${ }^{11}$ »propadel boš, šakal, propadla boš, ponorela zver, v jarku« (237). V monologu Krapilina se zariše glavna filozofska pozicija Bulgakova o obstoju višjega etičnega sodišča, ki bo vsakemu posamezniku sodilo po njegovih dejanjih. Razjarjeni Hludov ukaže kazen za Krapilina.

V nasprotju z romanom Bela garda, kjer so aluzije in navedki iz Razodetja razpršeni po celotnemu tekstu, se apokaliptični siže drame Beg skoraj v celoti opira na podobo generala Hludova, ki ga je Bulgakov z rabo medbesedilnih sklicev na Razodetje prikazal kot apokaliptično zver in odrešitelja istočasno. Prav številni apokaliptični elementi Hludova označijo kot rablja, ki sčasoma sam postane žrtev, zaradi česar se njegova tragična usoda bralca toliko bolj dotakne in ga pretrese. V Begu namreč večina medbesedilnih navezav, ki se pojavljajo tako v Hludovovem »sanjskem « kot resničnem svetu, bralca opozarja na dvodimenzionalnost njegovega značaja. Svojo primarno nalogo - služenje domovini - vidi v obešanju, ki ga nekdo mora opravljati: »Kdo pa bo obešal!« (236). Obenem se nenadoma spomni na svojo mladost in pomilosti glavno junakinjo drame, Serafimo, ki ga zmerja s »šakalom« in »zverjo« (235).

$\mathrm{Na}$ koncu drugega dejanja se Hludovova odločnost zrahlja: zave se svoje zmote, se zgrozi nad svojimi dejanji in se sprašuje, če je bolan. Ko odhaja iz belogardističnega štaba, za sabo pusti sledi - temne vreče s trupli obešenih. $\mathrm{Na}$ tem mestu Bulgakov izpostavi razpad bistva človeške narave pod vplivom nekontroliranih zgodovinskih sil. Ko Hludov izgubi vero v svoje poslanstvo in Boga, postopoma prične izgubljati tudi razum. Ob tem je Bulgakov še posebej pozoren na stanje notranje zmedenosti človeka, ki izgublja povezave z zunanjim svetom. Pogubna moč vojne/zgodovine na Hludova deluje neposredno, saj je sam njen del in bije ne samo zgodovinsko, ampak tudi svojo bitko, bitko med realnostjo/budnostjo in sanjami. V razpadajočem se apokaliptičnem svetu se postopoma izgublja v neskončnem labirintu blodenj, prividov in halucinacij. $\mathrm{Ob}$ tem je potrebno poudariti, da je zgodovinska realnost $\mathrm{v}$ Bulgakovovi ustvarjalnosti zmeraj podobna nočni mori, v kateri se materializirajo stvari, ki so prej veljale za nedoumljive, razpad starega sveta, številni poboji, uničevanje in trpljenje. Podobno kot drugi Bulgakovovi junaki, Hludov postane priča vseobsegajočemu razpadanju in se začne odmikati v dvomljiva svetova fantazije in resničnosti hkrati. Njegova dejanja nadzoruje neizprosen občutek strahu in hrepenenja, nelagodja in obupa. Razpad človeškega v človeku pod vplivom nekontroliranih zgodovinskih sil povzroči tragično razdvojenost osebnosti, ki se utaplja v poskusih samoupravičevanja. Številni postopki uvajanja dvojnikov,

${ }^{11}$ Podoba zmedenega, blaznega preroka postane stalnica Bulgakovovih del. 
zrcaljenja, obstoja na meji med sanjami in realnostjo, nespečnost, nekontroliran strah, problematizirajo vpliv zunanjega sveta na človekovo duševno stanje. Za nepravične kazni je Hludov obsojen na večno mučenje vesti, ker je izdal svojo dušo in podlegel zverinskemu kaosu zgodovine in nadrejene oblasti. ${ }^{12}$ Nravstveno načelo premaga strahove in blodnje šele na koncu drame, ko se Hludov dokončno zave svojih zločinov in si sodi sam.

Poleg aluzij na Razodetje, ki poudarjajo pomen celotnega dogajanja kot zadnjega stadija pred uresničitvijo apokalipse, se v drugem dejanju pojavljajo aluzije na izhod izbranega naroda k obljubljeni deželi. Bulgakov vzpostavi paralelo med generalom Hludovim, ki rešuje preostanke bele garde, in Mojzesom, ki je bil poklican, da odpelje svoj narod v obljubljeno deželo. Aluzije se okrepijo z navedki iz Stare zaveze, ki jih citira Hludov v pogovoru s svojim nadrejenim. Ponovno smo priča ambivalentnosti, saj Hludov ne verjame več v odrešitev in namesto v obljubljeno deželo svoj narod odpelje v mesto greha - Konstantinopel ter ga tako obsodi na nadaljnje preizkušnje. Pomen aluzije na izhod v obljubljeno deželo se prav tako travestijno zniža v pogovoru med Hludovim in njegovim nadrejenim, saj beg bele garde primerja z begom ščurkov (247).

Aluzije na Razodetje se pojavijo tudi v tretjem in četrtem dejanju drame, ki se odvijata v Konstantinoplu in Parizu. Na koncu drugega dejanja glavni junaki zapustijo domovino in odplujejo $\mathrm{v}$ Konstantinopel, ki je na začetku tretjega dejanja predstavljen kot mesto greha in kot babilonska vlačuga iz Razodetja, »grozno, temačno in zadušljivo mesto« (263). Bulgakov namensko ponazori kaotičnost prizorišča dogajanja $z$ uporabo večjezičnih povedi $v$ francoščini, italijanščini, angleščini in turščini. S tem poudari nesoglasje, nerazumevanje in kaos, ki vladajo Konstantinoplu. V tem razuzdanem mestu trgovcev, beguncev, beračev, kockarjev in prostitutk se glavni junaki popolnoma izgubijo. Namesto izhoda v obljubljeno deželo so obsojeni na stradanje, trpljenje in poniževanje. Tok zgodovine, ki v Bulgakovovi ustvarjalnosti neustavljivo kroji življenje in delovanje posameznika, pripelje do paradoksalne zamenjave vlog, odigranih v prvih dejanjih: Hludov, ki je še pred kratkim obešal nasprotnike in veljal za odločnega in krutega belogardističnega generala, postopoma izgublja razum in se spremeni v bolnega, nesrečnega človeka; njegov prijatelj general Čarnota prodaja ročno izdelane figurice in zapravlja denar $\mathrm{v}$ hazarderskih igrah, njegova partnerica se preživlja s prostitucijo, idealistični docent Sergey Golubkov brezciljno tava po mestu, njegova ljubljena Serafima pa se odloči postati prostitutka, pred čimer jo reši Hludov.

$\mathrm{Na}$ koncu drame se vnovič zariše tema nesmiselnosti bega pred zgodovino in usodo. O tem se sprašuje Serafima: »Kam, zakaj smo bežali? /.../ Želim vse pozabiti, kot da tega ne bi bilo!« (276). V nasprotju s prekletim Konstantinoplom se podoba Rusije $\mathrm{v}$ zavesti junakov zariše kot idealiziran metafizični kraj, zadnje pristanišče in končni cilj, kamor se morajo na vsak način vrniti: »Minil bo

${ }^{12} \mathrm{~V}$ zadnjem Bulgakovovem romanu Mojster in Margareta se je z istim problemom soočil Poncij Pilat, ko je ukazal usmrtiti pravičnika, človeka, ki je kriv samo tega, da govori resnico. 
mesec, prispeli bomo, vrnili se bomo /.../ (276). Novi Jeruzalem iz Razodetja in obljubljena dežela iz Stare zaveze se na koncu drame zlijeta v celoto in asociirata na zapuščeno Rusijo. Na tem mestu se spet izpostavi Bulgakovovo stališče videnja zgodovine kot zaporedja nenehno se ponavljajočih dogodkov in shem. Če so v prvih dejanjih junaki na vsak način želeli zbežati iz Rusije, v zadnjem dejanju načrtujejo svojo vrnitev. Zgodovinski krog se bo spet sklenil, ob tem pa ostaja odprto vprašanje o tem, kaj jih čaka po vrnitvi v domovino.

Hludov je edini, ki vzame usodo v svoje roke in se izogne nadaljnjemu begu. Sprva se odloči vrniti v Rusijo in se predati boljševikom, toda na koncu drame si sodi sam. Usoda ostalih junakov ostaja nejasna.

\section{Zaključek}

Ob tekstovni analizi drame Beg postane jasno, da predstavlja najpogostejšo intertekstualno figuro aluzija, ki opredeljuje stičišča med apokaliptično prerokbo in Bulgakovovim tekstom in je $\mathrm{v}$ večini primerov ambivalentne narave. Analiza drame pokaže, da Bulgakov ne verjame $\mathrm{v}$ enotnost pomena ali interpretacije kakršnekoli situacije, prerokbe ali podobe, celo tradicionalno biblijske ne. V nasprotju z binarnim razmišljanjem delitve na dobro in zlo si Bulgakov prizadeva za dvoplastni, večpomenski, sakralno-infernalni model sveta, v katerem ne obstajajo enkrat in za vedno opredeljeni kontrasti. Pluralnost sistema odnosov med različnimi kategorijami literarnega sveta Bulgakova predpostavlja večstransko vrednotenje evangelijskih in apokaliptičnih elementov: hudič ne pomeni samo utelešenega zla, svetloba ne pomeni zgolj odrešitve, mesto nikoli ni podobno samo Novemu Jeruzalemu, zver se lahko pokesa in ji je odpuščeno. To so bolj ali manj priznana dejstva.

Ob teh pa nesporno ostaja ob strani neka druga, nič manj pomembna lastnost Bulgakovove drame Beg. Za razliko od drugih sodobnikov pri Bulgakovu ni zaslediti vzhičenja nad očiščevalno silo revolucije in državljanske vojne. $\mathrm{Za}$ sovjetski gledališki prostor, gojišče ideološko usmerjenih stereotipnih podob, predstavlja drama Beg nenavaden pojav. Namesto strogo začrtane delitve na rdeče in bele se pred nami razgrne Bulgakovova lastna, apokrifna prerokba, ki ne vsebuje monolitnih, ustaljenih smernic, temveč samo gibljive, večplastne in prepletajoče se paralele. Ob tem postane jasno, da pisatelj kategorično ne sprejema nasilja in z obžalovanjem vzpostavlja zgodovinsko paralelo med preteklostjo Rusije, polno krvavih uporov, in sedanjostjo, ki se prav tako utaplja $\mathrm{v}$ nasilju in krvi. 


\section{LITERATURA}

Михаил БУЛГАКОВ, 1994: Пьесы 1930-х годов. Санкт-Петербург: Искусство.

Борис ГАСПАРОВ, 1994: Литературные лейтмотивы. Очерки русскойлитературы 20. века. Москва: Наука.

--, 1994: Новый Завет в произведениях М. А. Булгакова. Москва: Литературные мотивы.

Miha JAVORNIK, 1992: M. A. Bulgakov - umetnost, zgodovina, fiktivno ali realno. Slavistična revija 40/1, 79-101.

- -, 1994: Evangelij Bulgakova: O ustvarjalnosti Mihaila Afanasjeviča Bulgakova. Ljubljana: Znanstveni inštitut Filozofske fakultete.

Николай КОЗЛОВ, 1990: Пьеса из восьми снов (о »Беге« Михаила Булгакова). Содержательность форм в художественной литературе. Проблемы жанра. Куйбышев, $103-117$.

Михаил РОТКОВ, 2004: Эсхатологический мотив в произведениях М. Булгакова о гражданской войне. Православие и русская литература. Арзамас, 157-164.

Alexander SKAZA, 1979/80: Fragment o dramatiki Mihaila Bulgakova. Jezik in slovstvo 6, 155-159.

--, 1981: Pripovedništvo in dramatika Mihaila Bulgakova. M. Bulgakov, Škrlatni otok, Moliere. Ljubljana.

Александр СМЕЛЯНСКИЙ, 1989: Драмы и театр М. Булгакова. Булгаков М. А. Собрание сочинений в 5. томах. Москва. Т.3, 573-702.

Борис СОКОЛОВ, 2003: Булгаков. Энциклопедия. Москва: Алгоритм.

Sveto pismo Stare in Nove zaveze: Razodetje (Apokalipsa). Ljubljana: Svetopisemska družba Slovenije, 2005. 276-297.

Вера ХИМИЧ, 2003: В мире Михаила Булгакова. Екатеринбург: Уральский Университет.

Мариетта ЧУДАКОВА, 1988: Жизнеописание Михаила Булгакова. Москва: Книга.

Евгений ЯБЛОКОВ, 1992: Лицо времени за стеклом вечности. Историософия Михаила Булгакова. Общественные науки и современность 3, 97-108.

\section{APOCALYPTIC COMPREHENSION OF REALITY IN MIKHAIL BULGAKOV'S DRAMA FLIGHT}

This research builds on the analysis of M. A. Bulgakov's drama "Beg" about the revolution and civil war in the former Soviet Union to advance an understanding of the influence of the Book of Revelation on Bulgakov's perception of the political situation in the former Soviet Union, in the time of a revolution and a Civil war. The analysis is intended to model the apocalyptic context in abovementioned literary works on the basis of the key intertextual figures (allusions and quotes) and to prove that Bulgakov intentionally invented them into his texts to construct his own apocalyptic vision of current

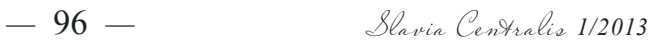


historical events. Metacommentary in his texts as well as critiques and statements of his contemporaries confirm that Bulgakov did not accept the new political regime and predicted an inevitable end to Russia. All these feelings are present in his literary works. The research establishes the presence of a covert apocalyptic conception, based on the structural and systematical organization of intertextual figures and motives taken from the Book of Revelation. Significantly, this apocalyptic conception establishes Bulgakov's eschatological perception of a historical process in the former Soviet Union. It should be noted that Bulgakov's mythological view differs significantly from the traditional Christian one. In this case, the question of the eternal struggle between Good and Evil is not essential because Bulgakov does not believe in the traditional binary opposition characteristic of Christian religion. Evil in his prose is seen as a part of the universe and good cannot exist without it. 